\title{
Análise de estratégias para a logística reversa: um estudo de caso sobre as sandálias Havaianas em São Paulo (SP) e João Pessoa (PB).
}

Analysis of strategies for reversal logistics: a case study on the Havaianas flip flops in São Paulo (SP) and João Pessoa (PB), Brazil.

\author{
Karlla VC Barbosa', Tatiane Magalhães Silingovski², Alexandra Alcantara Teixeira ${ }^{3}$, Renato De Giovanni ${ }^{4}$, \\ Thomaz Almeida ${ }^{5}$, Cristina Saddy Martins ${ }^{6}$, Alexandre Uezu ${ }^{7}$ \\ 1,2,3,4 Mestre em conservação ambiental e sustentabildade;, Escola Superior de Conservação Ambiental e Sustentabilidade - ECAS, Brasil \\ ${ }^{5}$ Biólogo, Escola Superior de Conservação Ambiental e Sustentabilidade - ECAS, Brasil \\ ${ }^{6}$ Doutora em Ecologia e coordenadora, Escola Superior de Conservação Ambiental e Sustentabilidade - ECAS, Brasil \\ ${ }^{7}$ Doutor em ecologia e professor, Escola Superior de Conservação Ambiental e Sustentabilidade - ECAS, Brasil
}

\section{Resumo}

O avanço da tecnologia e as atuais formas de marketing pressionam o mercado para um consumo exacerbado, o que induz à redução do ciclo de vida dos produtos e implica no seu rápido descarte. Novas estratégias sustentáveis buscam fechar o ciclo do produto no mercado através da logística reversa. Este trabalho analisou a predisposição do consumidor em devolver produtos pós-consumo mediante duas estratégias de coleta: devolução direta e coleta seletiva, utilizando como estudo de caso as sandálias Havaianas, um produto extremamente consumido nacionalmente. Foram realizadas 807 entrevistas em dois centros urbanos (390 em São Paulo e 417 em João Pessoa) e visitas em cooperativas de reciclagem das duas regiões. Do total de entrevistados mais de $80 \%$ declarou consumir as sandálias. Em São Paulo, dos $73 \%$ dos entrevistados que devolveriam as sandálias, 34\% o fariam sem necessidade de incentivo. Em João Pessoa, de $85 \%$ dos entrevistados que devolveriam o produto pós-consumo, $43 \%$ não precisariam de incentivo. Em São Paulo o potencial de captação através da coleta seletiva (60\%) é superior ao de devolução direta voluntária (40\%), sendo que em João Pessoa essas duas estratégias se equivalem. Concluímos que a devolução direta voluntária e a coleta seletiva são estratégias viáveis para a aplicação da logística reversa neste caso; mas um projeto piloto poderia avaliar melhor a eficácia; cooperativas de catadores podem ser um importante meio de captação de resíduos sólidos passíveis de reciclagem; a responsabilidade compartilhada entre a sociedade, poder público e privado pode contribuir para fechar o ciclo do produto; e a logística reversa pode ser vista como ferramenta estratégica de competitividade empresarial.

Palavras-chave: Logística reversa, Coleta seletiva, Reciclagem, Desenvolvimento sustentável.

\begin{abstract}
Advances in technology and marketing concepts have been contributing in reducing the life cycle of products and to their rapid discard. In the other hand, new sustainable strategies seek to close the product cycle in the market through reverse logistics. The present study aimed to examine the consumer's willingness to return consumed products through two strategies for collecting, using Havaianas sandals as a case study: direct return or selective disposal. A total of 807 questionnaires were administered in two large Brazilian cities, João Pessoa (390) and São Paulo (417), and recycling cooperatives were visited. In total, about $80 \%$ reported using the sandal. In São Paulo city, among the almost $73 \%$ that were willing to return the sandals, $34 \%$ would do it without any financial encouragement. In João Pessoa, among the $85 \%$ that would return the sandals, about $43 \%$ would not need any encouragement. In São Paulo, the potential for selective collection (60\%) is superior to direct voluntary return (40\%), and in João Pessoa both strategies are equivalent. We concluded that: both direct voluntary return and selective devolution are viable strategies, but a pilot project seems to be necessary to better evaluate the different strategies; cooperatives of collectors of recyclable materials may be a good alternative as a collaboration to collect the urban solid waste; the shared responsibility between society, government and companies is helpful for closing the cycle of materials; and the reverse logistic may play an important role in the business competitiveness.
\end{abstract}

Keywords: Reverse logistics, Collective disposal, Recycling, Sustainable development. 


\section{INTRODUÇÃO}

Nas últimas décadas o desenvolvimento tecnológico e a pressão por lançamento de novos produtos contribuíram fortemente para a redução do ciclo de vida dos produtos e seu rápido descarte, pois os novos lançamentos influenciam o consumo mesmo antes do final do ciclo de vida do lançamento anterior (BORCHARDT et al., 2008). O aumento na velocidade da substituição dos produtos provocou desequilíbrio entre as quantidades que são descartadas e as reaproveitadas, gerando um enorme crescimento de produtos pós-consumo. Esse comportamento da sociedade moderna resultou em um dilema ambiental: a dificuldade de disposição do lixo urbano (LEITE, 2009).

Segundo dados levantados em 2010 , cerca de $60 \%$ dos municípios brasileiros não destinavam adequadamente seus resíduos sólidos (REVISTA DA INDÚSTRIA, 2010). Estima-se que o volume total de lixo no país seja de 260 mil todo dia, e embora $80 \%$ desse resíduo possa ser aproveitado, uma parcela ainda muito pequena é destinada para reciclagem (CEMPRE, 2014). Considerando que o Brasil tem uma população de 201.032.714 habitantes (IBGE, 2014), a média de geração de resíduos sólidos per capita no país é de cerca de $0,8 \mathrm{~kg} / \mathrm{hab} / \mathrm{dia}$, sendo possível chegar a 1,5 $\mathrm{kg} / \mathrm{hab} / \mathrm{dia}$ nos grandes centros urbanos (CEMPRE, 2014).

A necessidade por novas alternativas de redução da quantidade de lixo e o destino adequado de embalagens pós-consumo impulsionou estudos que relacionam a geração, coleta, disposição e reciclagem dos resíduos urbanos (BERTHIER, 2003; PIETERS, 1991). Alguns trabalhos sugerem como parte da solução a reciclagem e reutilização de resíduos, sobretudo em decorrência do desenvolvimento tecnológico (ZANIN e MANCINI, 2004). Outros dão ênfase nas políticas públicas de tratamento dos resíduos e nos demais atores envolvidos na questão (GRIMBERG e BLAUTH, 1998; JACOBI, 2006).

A reciclagem apresenta resultados expressivos na esfera socioambiental e econômica. $\mathrm{O}$ termo reciclagem compreende o reaproveitamento de materiais ou polímeros, já beneficiados como matéria-prima e que por algum motivo foram rejeitados, sendo, por vezes, possível de voltarem ao estado original (CEMPRE, 2014). No meio ambiente a reciclagem pode reduzir o acúmulo de lixo e a extração de recursos naturais para a produção de novos produtos (BIDONE, 1999). No âmbito social, a reciclagem não só proporciona melhor qualidade de vida para a população, através das melhorias ambientais, como também tem gerado trabalho e receita para pessoas que vivem da coleta de produtos recicláveis (ALMEIDA et al., 2013). No aspecto econômico a reciclagem contribui com a utilização mais racional dos recursos naturais e a reposição daqueles recursos que são passíveis de reaproveitamento (REVISTA DA INDÚSTRIA, 2010; CEMPRE, 2010).

A porcentagem de materiais coletados e reciclados no Brasil é de apenas $12 \%$, o que representa uma perda de cerca de $\mathrm{R} \$ 8$ bilhões anuais em materiais que poderiam de alguma forma ser reaproveitados (SILVÉRIO, 2010).

Num dos locais deste estudo, a cidade de São Paulo, quase 12 mil toneladas de resíduos sólidos são coletadas diariamente, sendo esta talvez a cidade com maior geração de lixo do mundo (HOORNWEG E BHADA-TATA, 2012). No entanto, apenas um pouco mais de $58 \mathrm{t} / \mathrm{d}$ são destinadas para unidades de triagem para reciclagem pela prefeitura. A cidade atualmente conta com 21 centros de triagens cadastrados pela (PREFEITURA MUNICIPAL DE SÃO PAULO, 2014; IPEA, 2012). Em João Pessoa, também foco da pesquisa, são coletadas cerca de 3.200 toneladas de resíduos sólidos por dia, porém apenas 15 toneladas são destinadas para centro de triagem, sendo que o município conta com quatro núcleos de coleta seletiva (PREFEITURA MUNICIPAL DE JOÃO PESSOA, 2013; IPEA, 2012).

\section{I A LOGÍSTICA REVERSA E O MERCADO BRASILEIRO}

A Logística Reversa consiste no conjunto de operações relacionadas ao reuso de produtos industriais (LEITE, 2009) e tem se tornado cada vez mais uma ferramenta estratégica de competitividade empresarial. O tema é um assunto recorrente na literatura de gestão de redes de suprimentos (ROGERS e TIBBEN-LEMBKET, 2001; STOCK e MULKI, 2009), sendo utilizada também com o intuito de agregação de valor econômico. As empresas que têm uma visão futura de mercado buscam cada vez mais integrar em suas atividades os pilares da sustentabilidade: econômico, social e ambiental - triple bottom line (ELKINGTON, 1997). Além disso, a disposição ou reutilização dos resíduos da produção pode ser vista como uma nova oportunidade de negócio.

Estudos sobre logística reversa demonstraram a disponibilidade do consumidor em fazer parte 
desse sistema, principalmente quando esse é baseado numa política de retorno transparente (ARAUJO et al., 2013; SKINNER et al., 2008). Quando feita dessa forma, a empresa também é beneficiada com obtenção de vantagens competitivas e melhor desempenho no varejo (SKINNER et al., 2008).

Os "canais de distribuição reversos de pós-consumo" são responsáveis pelo processamento e comercialização dos produtos "inservíveis" (estágio após utilização e descarte), desde sua coleta até sua reintegração ao ciclo produtivo como matéria-prima secundária. Em teoria, os canais reversos de pós-consumo subdividem-se em canais reversos de (i) reuso de bens duráveis e semi-duráveis, (ii) remanufatura de bens duráveis e (iii) de reciclagem dos produtos ou de seus materiais constituintes. Tal classificação é dada em função da vida útil dos materiais, onde duráveis pode significar uma vida útil de décadas; semiduráveis, anos; e descartáveis, semanas (LEITE, 2009).

Com o aumento da preocupação ambiental na sociedade surgiram tendências de consumo que buscam conciliar as demandas individuais e o limite dos recursos naturais (MONTEIRO, 2010; MMA, 2010). A busca por um consumo mais consciente é uma reação da sociedade, que vem observando questões como: desperdício; aumento em larga escala do lixo; crescimento desordenado de produtos comercializados; processos produtivos insustentáveis; e utilização excessiva de matéria prima. Tal reação repercute em mudanças de hábitos de consumo e não apenas na quantidade de produtos comprados, como também na valorização de produtos de empresas que demonstram preocupações socioambientais (AKATU, 2010). A logística reversa se apresenta como uma nova estratégia sustentável, que busca mecanismos que fechem o ciclo dos produtos no mercado.

\section{I.2 ESTUDO DE CASO DE LOGÍSTICA REVERSA DAS SANDÁLIAS HAVAIANAS}

As sandálias Havaianas, produto com grande penetração e mercado, acessível a todos os públicos e utilizado não só no Brasil como também em 80 países no exterior, são compostas por solado de borracha de fabricação própria e tiras de PVC. Atualmente 100\% dos resíduos industriais de PVC são reaproveitados e 80 a $90 \%$ das aparas da borracha são reincorporadas ao processo produtivo, sendo o restante utilizado como combustível por uma indústria de cimento. Segundo dados da empresa, em 2009 foram produzidos 178.500 .000 de pares de sandálias, dos quais 160 milhões foram destinados ao mercado brasileiro. O desafio atual da empresa é encontrar uma destinação adequada ao produto pós-consumo (Alpargatas - Setor de Marketing Havaianas, comunicação pessoal).

Devido à relevância do tema logística reversa e sua importância socioambiental, este trabalho fez um estudo de caso com as sandálias Havaianas, com objetivo de analisar a pré-disposição do consumidor em devolver o produto pós-consumo através de duas diferentes estratégias de coleta: devolução direta ou coleta seletiva em dois centros urbanos (São Paulo - SP e João Pessoa - PB).

Para a compreensão desta pré-disposição de retorno, buscou-se identificar: (i) o perfil do consumidor (escolaridade, faixa etária, gênero e renda familiar); (ii) os hábitos de consumo (quantidade de produtos adquiridos e locais de compra), bem como os hábitos de descarte (local e frequência de descarte); (iii) a predisposição do consumidor em devolver voluntariamente o produto usado e em quais lugares estariam dispostos a ir, estimando o potencial de retorno por esta via; (iv) o impacto na predisposição caso sejam oferecidos estímulos adicionais; (v) a abrangência da coleta seletiva nos locais estudados e os atores sociais engajados; vi) a estimativa da quantidade de sandálias descartadas; e (vii) o funcionamento da coleta seletiva e a análise de viabilidade desta via para a captação do produto pós-consumo.

\section{MÉTODO}

Duas estratégias de coleta para as sandálias Havaianas foram investigadas em busca do melhor cenário para a logística reversa. A primeira estratégia verificou a possibilidade de devolução direta pelos consumidores e a segunda analisou a viabilidade por meio da coleta seletiva.

Como forma de obtenção dos dados, foi aplicado um questionário estruturado (Anexo I) com questões abertas e fechadas com o intuito de comparar realidades distintas, considerando-se aspectos culturais, econômicos, geográficos e climáticos nos dois locais de estudo, São Paulo e João Pessoa. As entrevistas foram realizadas em locais públicos, selecionados para abranger a maior diversidade de pessoas, ou seja, com faixa etária, renda familiar e escolaridade diversificada. Procurou-se realizar a mesma quantidade de entrevistas em centros comerciais e financeiros em dias da semana, bem como 
em áreas de lazer nos finais de semana. Em São Paulo os questionários foram aplicados em quatro pontos: Parque do Ibirapuera, Avenida Paulista, Parque Ecológico do Tietê e Praça da República. Em João Pessoa as quatro localidades selecionadas foram: Praia do Bessa, Praia do Cabo Branco, arredores do Manaíra Shopping e zona central da cidade.

Além de entrevistas com os consumidores, também foram realizadas visitas nas cooperativas de reciclagem para levantamento de informações sobre as ações, instalações, nível de abrangência e a logística de transporte e armazenamento das cooperativas. Também utilizou-se questionário estruturado (Anexo II) com questões abertas e fechadas. Em São Paulo as cooperativas visitadas foram: Coopere-Centro, Cooperativa Sem Fronteiras, Catasampa, Cooperativa União e Cooperleste. Em João Pessoa, foram entrevistadas cooperativas e grupos de catadores de matérias recicláveis, que estão locados nos bairros denominados Roger, Bessa e Cabo Branco.

As entrevistas nos dois locais foram planejadas com um tamanho amostral de forma a obter um erro máximo de $5 \%$ nas proporções estimadas considerando-se um intervalo de confiança de $95 \%$ e o valor mais conservador possível para cada proporção $(0,5)$.

\section{RESULTADOS E DISCUSSÃO}

\section{I Disposição em participar de um programa de logistica reversa - São Paulo e João Pessoa}

Em São Paulo foram realizadas 390 entrevistas em quatro localidades da cidade de grande movimento e passagem de pessoas de diferentes regiões (Figura 1A), buscando assim atingir um público-alvo diversificado. Dos entrevistados, $83 \%$ declararam usar as sandálias Havaianas. Cada consumidor possui em média de dois a três pares das sandálias, sendo a frequência média do descarte igual a um par a cada dez meses. Nas entrevistas foi possível observar que o perfil dos consumidores é bastante diverso, abrangendo diferentes faixas etárias, escolaridades, classes econômicas (de acordo com ABEP, 2010) e sexo (Figuras 2, 3, 4 e 5).

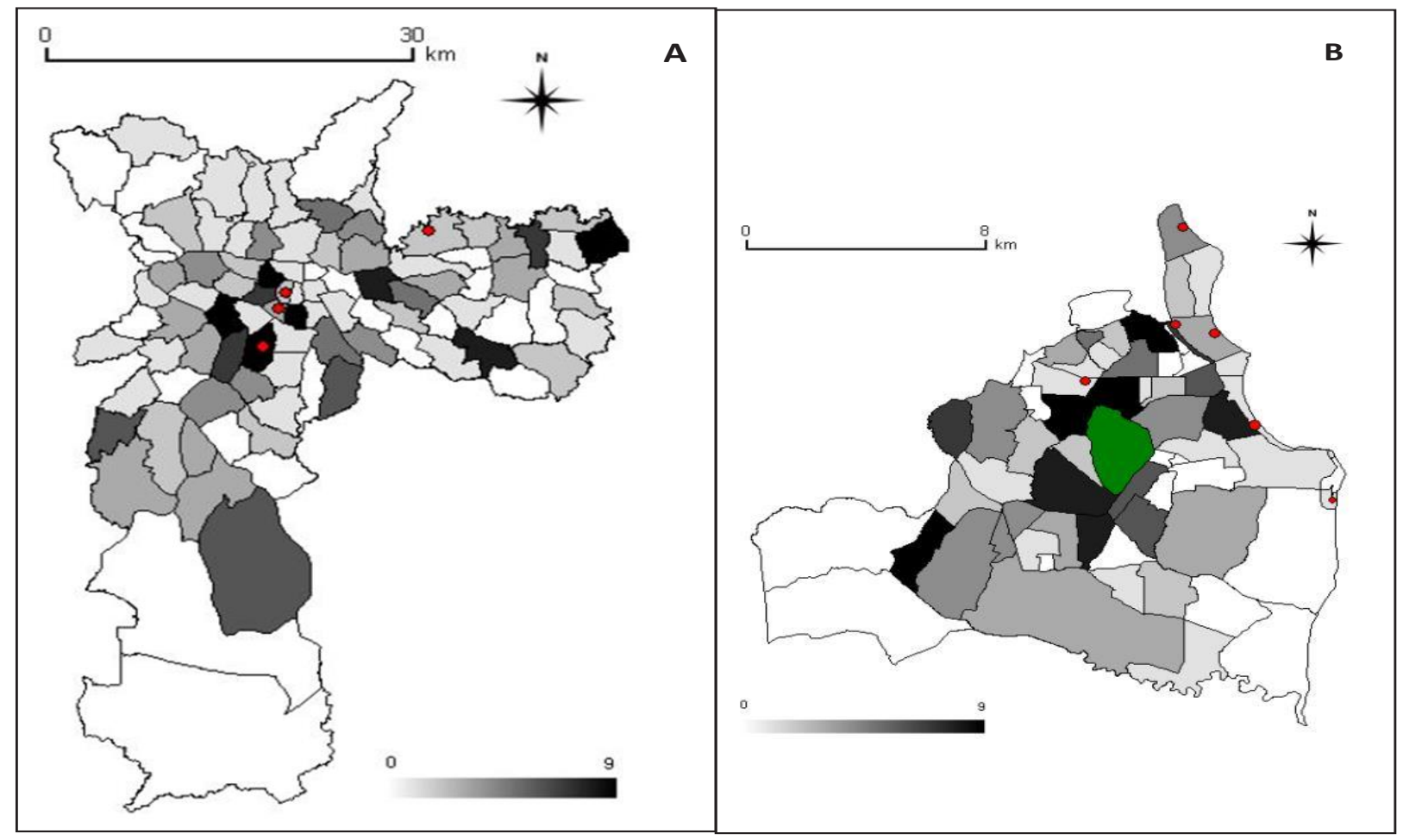

Figura 1 - Número de entrevistados por distrito: A - São Paulo, SP, e B - João Pessoa, PB. Tonalidades mais escuras indicam maior quantidade de moradores entrevistados. Pontos vermelhos indicam locais das entrevistas. Em B a área central em verde indica a localização da Mata do Buraquinho. Mapa de bairros fornecido pela Divisão de Geoprocessamento e Cadastro da Secretaria de Planejamento da Prefeitura de João Pessoa através do site Jampa em Mapas. 


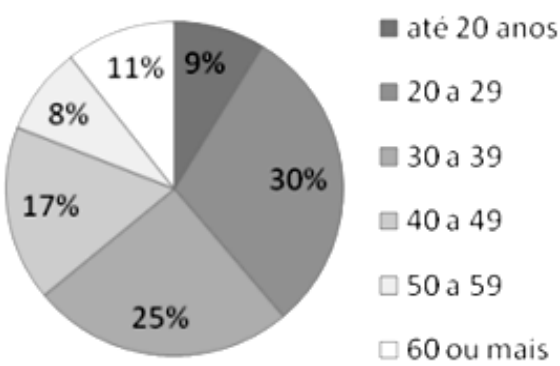

Figura 02 - Perfil dos entrevistados de acordo com a faixa etária (São Paulo).

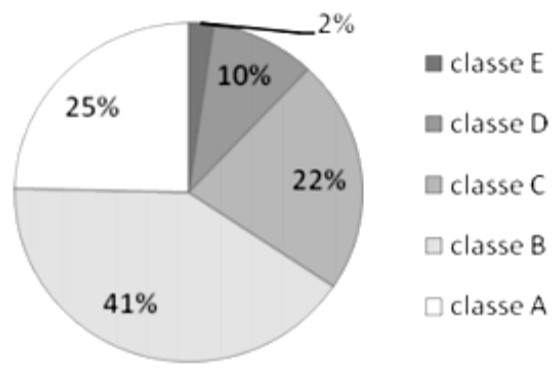

Figura 04 - Perfil dos entrevistados de acordo com a renda familiar (São Paulo). Classes econômicas segundo estimativas da ABEP, 2010.

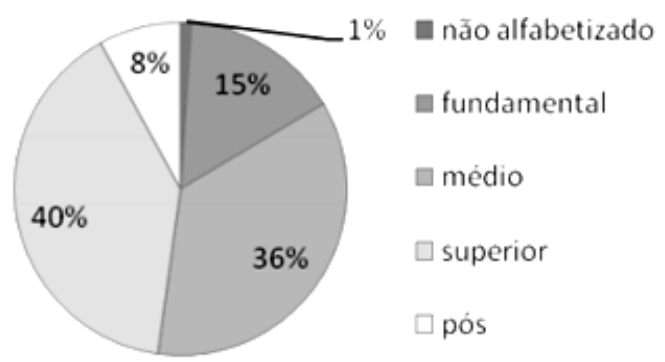

Figura 03 - Perfil dos entrevistados de acordo com o nível de escolaridade (São Paulo).

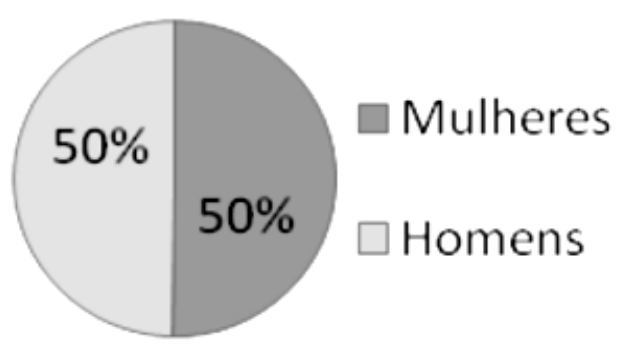

Figura 05 - Perfil dos entrevistados de acordo com o sexo (São Paulo).

Em João Pessoa foram realizadas 417 entrevistas, em pontos de grande movimento e de público alvo diversificado (Figura 1B). O perfil dos consumidores foi abrangente (figuras 6, 7, 8 e 9), sendo que dos entrevistados, $89 \%$ declararam usar Havaianas. Cada consumidor possui entre dois e cinco pares das sandálias, sendo a frequência média de descarte igual a um par a cada cinco meses.

Os resultados mostraram que $34,6 \%$ do total de entrevistados na cidade de São Paulo e 43,7\% na cidade de João Pessoa estariam dispostos a devolver voluntariamente as sandálias pós-consumo, sem a necessidade de receber qualquer tipo de incentivo. Apenas $0,9 \%$ dos entrevistados em São Paulo e 1,1\% em João Pessoa disseram não se dispor a devolver as sandálias usadas.

Não foi constatada relação entre a predisposição à devolução direta voluntária e a escolaridade, pois a quantidade de consumidores não alfabetizados ou com pós-graduação entrevistados foi proporcionalmente baixa em relação aos demais níveis de escolaridade. Também não foi possível constatar se existe relação entre a predisposição à devolução voluntária direta e a renda familiar dos consumidores na cidade de São Paulo (Figuras 10A e 10B).

Em João Pessoa a mesma amostragem mostrou-se mais uniforme, sendo verificada uma tendência de menor propensão à devolução voluntária em classes econômicas mais altas $(b=-8,96 ; t(3)=$ $-3,631 ; p<0,05)$. No entanto, espera-se que o potencial de captação através da devolução direta voluntária possa crescer com campanhas de consumo mais consciente e responsabilidade socioambiental entre os consumidores.

A frequência anual de descarte declarada nas entrevistas pode ser extrapolada para a população da cidade, obtendo-se assim uma estimativa da quantidade total de pares descartados anualmente. Considerando-se a população de aproximadamente 11 milhões e 253 mil habitantes em São Paulo (IBGE, 2014), estima-se que sejam descartados 8,2 milhões de pares de sandálias Havaianas por ano na cidade. Já em João pessoa, extrapolando a proporção de entrevistados em cada frequência anual de descarte para uma população de aproximadamente 700 mil habitantes (IBGE, 2009), estima-se que sejam descartados um milhão de pares de sandálias por ano.

Do total de consumidores entrevistados, 79\% na cidade de São Paulo e 69\% na cidade de João Pessoa, disseram dispor de serviço de coleta seletiva de lixo domiciliar em algum nível, seja por coo- 


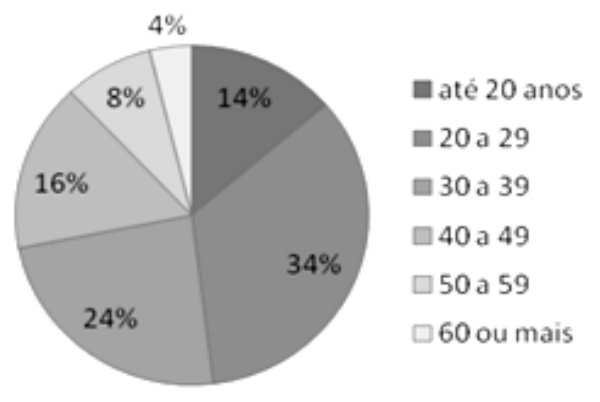

Figura 06 - Perfil dos entrevistados de acordo com a faixa etária (João Pessoa).

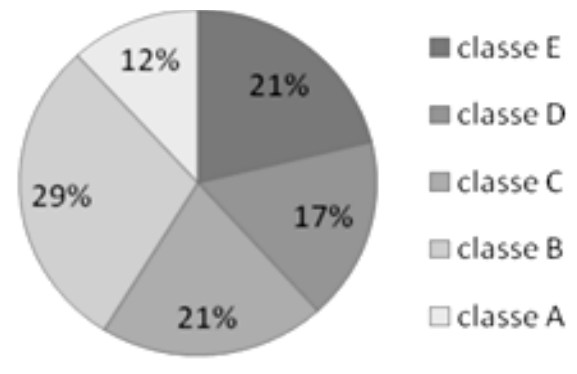

Figura 08 - Perfil dos entrevistados de acordo com a renda familiar (João Pessoa). Classes econômicas segundo estimativas da ABEP, 2010.

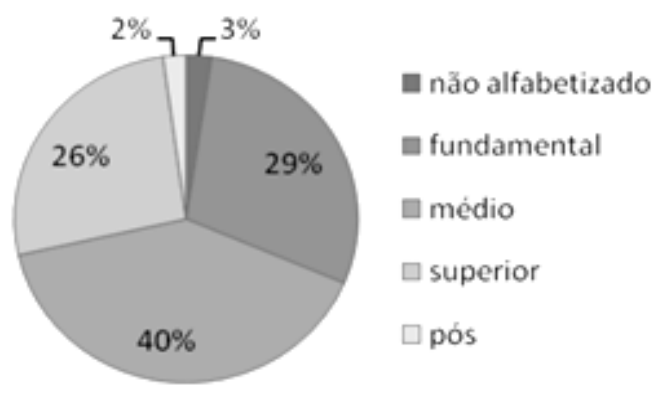

Figura 07 - Perfil dos entrevistados de acordo com o nível de escolaridade (João Pessoa).

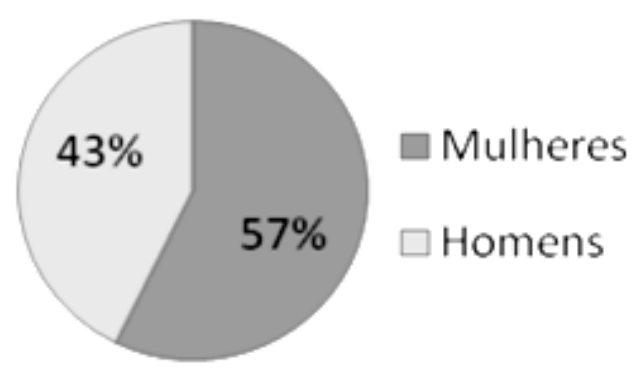

Figura 09 - Perfil dos entrevistados de acordo com o sexo (João Pessoa).

perativa de catadores, seja por serviços municipais.

Através da frequência de descarte de cada consumidor e extrapolando os dados para a população de cada cidade, foi possível estimar a quantidade de pares de sandálias que seriam retornadas em cada cenário: 1) devolução direta voluntária, 2) via coleta seletiva por pessoas que separam o lixo reciclável, ou 3) devolução direta a partir de incentivos (Figuras 11 e 12).

As preferências para locais de devolução e tipos de incentivo para devolução também foram obtidas através das entrevistas. Os supermercados foram apontados como o local mais adequado para
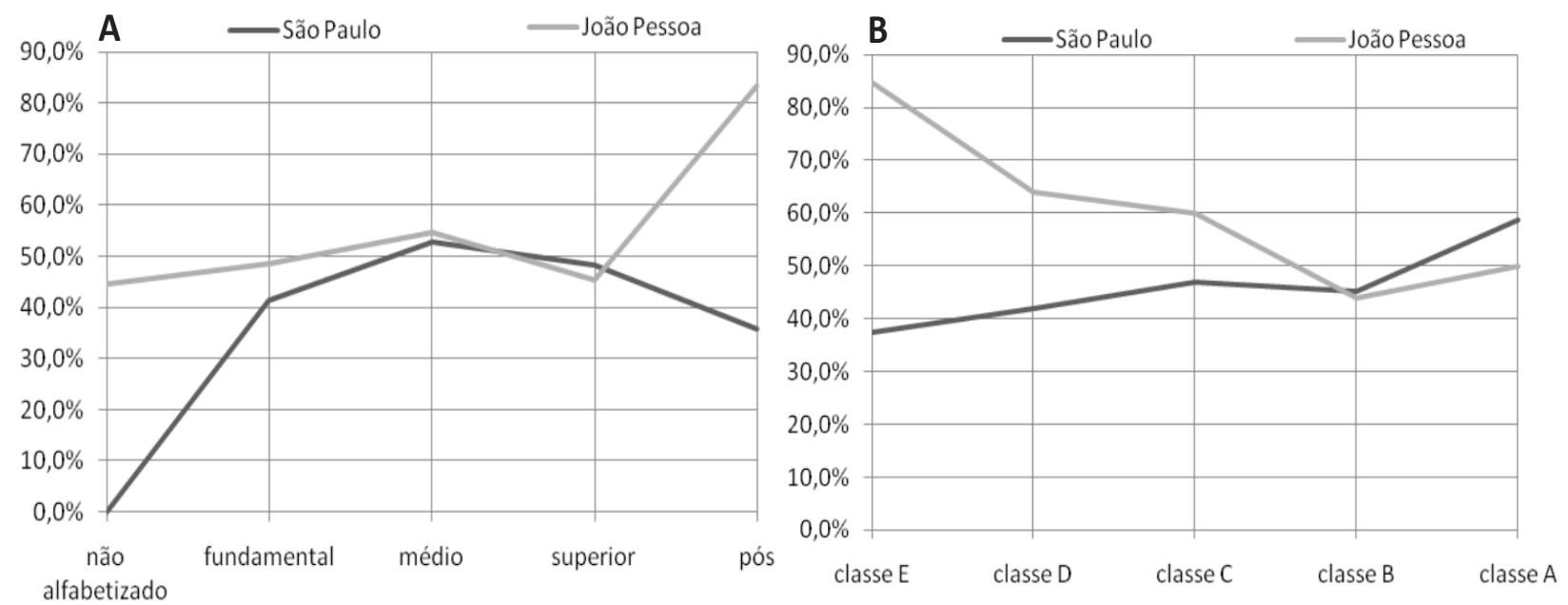

Figura 10 - Porcentagem de consumidores que devolveriam voluntariamente: A - em função da escolaridade e B - função da renda familiar (classes econômicas segundo estimativas da ABEP, 2010). 


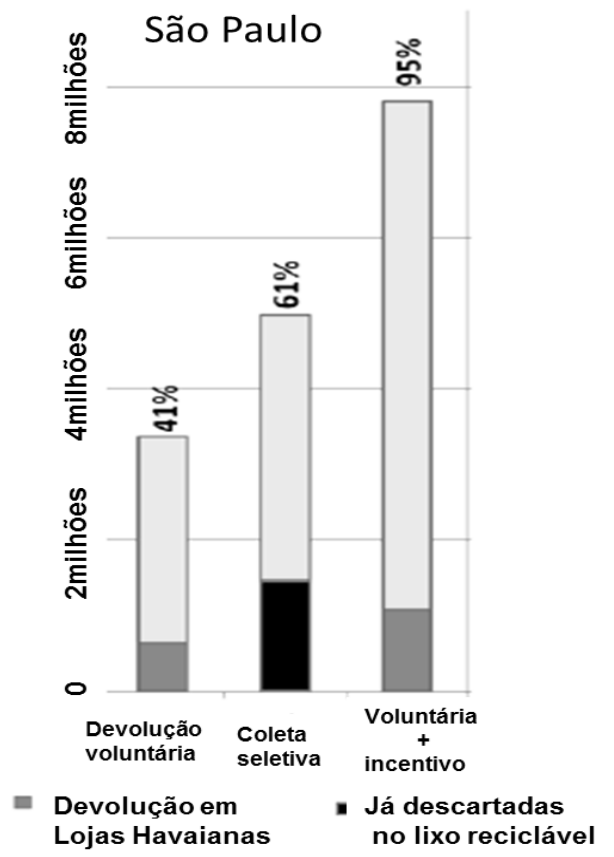

Figura 11 - Potencial de captação de sandálias Havaianas pós-consumo na cidade de São Paulo.

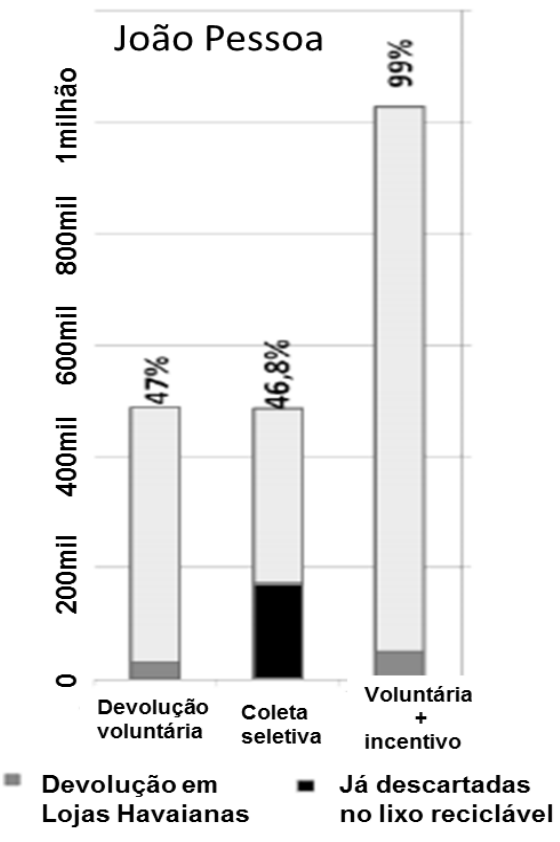

Figura 12 - Potencial de captação de sandálias Havaianas pós-consumo na cidade de João Pessoa.

devolução, seguidos de pontos de coleta em locais públicos e lojas da marca (Figura 13). A possibilidade de obter desconto na aquisição de novos produtos foi indicada como o incentivo mais atraente para devolução (Figura 14).

\subsection{COOPERATIVAS DAS CIDADES DE SÃO PAULO E JOÃO PESSOA}

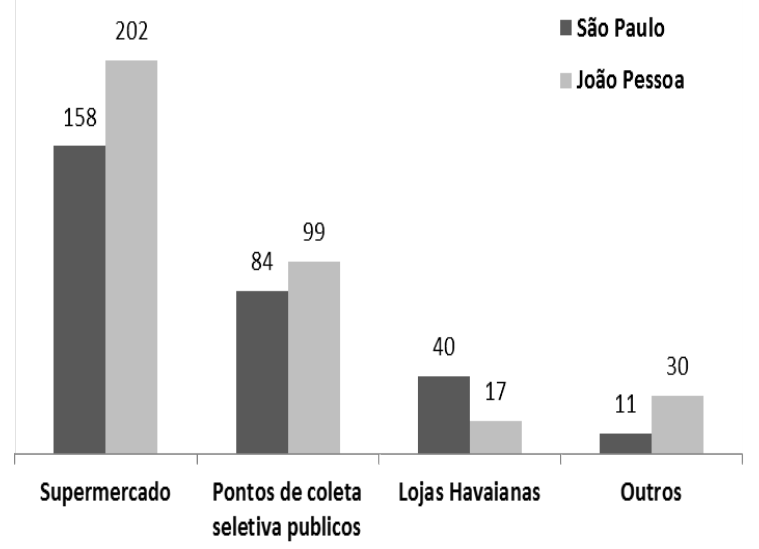

Figura 13 - Preferências de locais de devolução de sandálias pós-consumo (número de entrevistados) nas cidades de João Pessoa e São Paulo. O item "outros" inclui agências de correios, escolas e praias. Os entrevistados puderam escolher mais de uma alternativa.

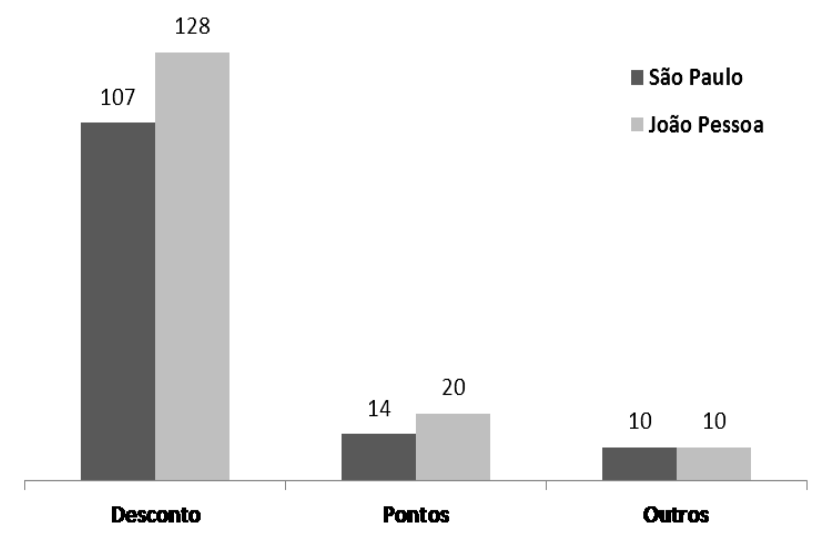

Figura 14 - Preferências de incentivos para devolução de sandálias pós-consumo (número de entrevistados) nas cidades de João Pessoa e São Paulo. O item "pontos" representa algum tipo de programa em que cada cliente acumula pontos a cada par devolvido, podendo no futuro trocar os pontos por algum benefício. $\mathrm{O}$ item "outros" inclui brindes e reverter renda para projetos sociais. Os entrevistados puderam escolher mais de uma alternativa. 
Foram realizadas visitas a cinco cooperativas na cidade de São Paulo: União, Cooperecentro, Catasampa, Cooperleste e Sem Fronteiras, que demonstraram modelos distintos de atuação apesar das mesmas condições estruturais. Todas as cooperativas recebem subsídios da Prefeitura da cidade, auxiliando nas despesas com aluguel dos galpões, água e luz. Receberam ainda, cada uma delas, a doação de um caminhão de coleta do lixo.

No sistema administrativo adotado pela maioria das cooperativas existe um revezamento da gestão entre os cooperados, com a formação de Conselhos de coordenadores, os quais exercem suas funções de conselheiros juntamente com as atribuições operacionais dentro da cooperativa. Algumas cooperativas como Cooperecentro e Catasampa possuem um trabalho de inclusão social, além de realizar divisão igualitária dos lucros entre os cooperados, independente da função exercida. Na Cooperecentro os moradores de rua são trazidos para cursos de capacitação elaborados internamente, muitas vezes sendo auxiliados inclusive na obtenção de documentos pessoais, quando necessário.

$\mathrm{Na}$ cidade de João Pessoa foi observada uma iniciativa semelhante com relação aos subsídios governamentais, onde cada cooperativa é beneficiada com um galpão dotado de abastecimento de água e energia elétrica. Por outro lado as cooperativas caracterizam-se por uma gestão individualizada: cada cooperado dispõe de um repartimento (box), que é ocupado por um cooperado ou por uma equipe (normalmente familiar), onde armazenam seus materiais coletados, havendo ainda a possibilidade de cada cooperado comercializar seus materiais por conta própria.

Tanto em São Paulo quanto em João Pessoa durante todas as visitas foram observados exemplares das sandálias Havaianas descartadas nos volumes de lixo das cooperativas. Em apenas dois casos, representantes das cooperativas estimaram empiricamente a quantidade de sandálias pós-consumo acumuladas: 01 "bag" semanal na Cooperecentro e um "bag" mensal na Cooperativa União, computados $1 \mathrm{~m}^{3}$ (um metro cúbico) para cada "bag" - ambas cooperativas paulistanas.

Os resultados indicam que tanto o cenário de devolução direta voluntária quanto o da captação através de coleta seletiva de resíduos são viáveis. Os consumidores estão dispostos a entregar o produto pós-consumo, ao invés de dar outro destino ao resíduo, seja com divulgação e oferta de pontos de entrega, seja através da coleta por cooperativas, e a logística reversa pode ser uma importante ferramenta de destinação consciente.

Em João Pessoa o potencial de captação nos dois cenários analisados foi praticamente equivalente, com uma pequena vantagem para a devolução direta voluntária. Em São Paulo o potencial de captação através da coleta seletiva é superior ao de devolução direta voluntária. Talvez essa diferença se dê ao fato de uma maior dificuldade que a população encontra de chegar aos pontos de coleta, devido às diferentes proporções no tamanho das cidades, ou por consequência de um engajamento maior da população nos hábitos de coleta seletiva de lixo reciclável. Além disso, constatamos que as cooperativas de São Paulo estão mais bem estruturadas e em maior número do que aquelas levantadas em João Pessoa. Os resultados sugerem que entre a devolução direta voluntária e a coleta seletiva, São Paulo apresenta condições mais favoráveis para um projeto piloto envolvendo a coleta seletiva na captação das sandálias pós-consumo.

O potencial de captação por devolução direta é baixo (menos de 10\% do volume total) se considerarmos a devolução apenas em lojas particulares. Neste caso, tendo por objetivo tornar a captação mais efetiva, seria necessário o desenvolvimento de parcerias com o poder público e o setor privado, para que postos de coletas estejam disponíveis em áreas diversas nas cidades (parques públicos, escolas, e supermercados). Nas entrevistas os supermercados foram apontados como o local de maior facilidade para a devolução direta voluntária.

As cidades onde foram feitas as pesquisas são centros urbanos que dispõem de estruturas logísticas do comércio mais bem estabelecidas e presença de cooperativas ativas, talvez por isso os resultados tenham sido satisfatórios quanto às alternativas propostas para logística reversa. Além disso, centros urbanos dispõem de locais de grande passagem de pessoas o que facilitaria a instalação de "ecopontos" (contentores de diferentes cores que são utilizados para separação de resíduos sólidos passíveis de reciclagem).

Em São Paulo, as grandes dimensões da cidade demandariam uma ampla capilaridade logística para a coleta das sandálias pós-consumo. Neste quesito João Pessoa apresentaria melhores condições para a devolução direta voluntária, não apenas pelas menores dimensões territoriais da cidade, mas também por possuir maior potencial de captação por esta via em comparação com São Paulo.

Nos dois municípios o potencial de captação de sandálias Havaianas pós-consumo aumenta 
consideravelmente no caso de devolução direta a partir de incentivos, atingindo praticamente o volume total descartado anualmente. Apesar de atrativo ao consumidor, entendemos que esse tipo de incentivo não educa para uma consciência prática da destinação adequada dos produtos consumidos a serem descartados.

Mesmo com o baixo percentual de lixo urbano efetivamente reciclado, entendemos que a coleta seletiva seja a melhor opção em longo prazo. Por outro lado, hoje o aumento na quantidade de material retornado dependeria necessariamente do aumento da infraestrutura e na eficiência da coleta. Cooperativas de catadores podem ser um importante meio de captação de resíduos sólidos passíveis de reciclagem, como já foi estudado por diversos autores (por exemplo, ALMEIDA et al., 2013; AQUINO et al., 2009). No entanto, para que as cooperativas consigam sobreviver é preciso apoio externo, seja do poder público ou privado, pois o atual modelo de negócio por vezes não é o suficiente para que estas consigam manter-se e oferecer um sistema completamente eficiente.

\section{CONCLUSÃO}

Neste estudo de caso, com as sandálias Havaianas, ambos os cenários pesquisados como alternativas de captação do produto pós-consumo, a devolução direta por parte dos consumidores e o uso da coleta seletiva, mostraram-se viáveis. Entretanto, a implantação de um projeto de logística reversa, para produtos amplamente consumidos e com alto volume de descarte, como o observado para as sandálias Havaianas, certamente envolverá inúmeros detalhes e aspectos que dificilmente podem ser previstos. Desta forma, sugere-se a realização de um projeto piloto para cada uma das estratégias analisadas, o que permitiria uma melhor avaliação do desempenho de cada um desses canais, especialmente antes de uma possível implantação da logística reversa em escala nacional.

Pelos nossos dados, São Paulo apresenta melhores condições para a captação através de coleta seletiva, ao passo que João Pessoa seria mais indicada para devolução voluntária. Havendo necessidade de optar por apenas um formato, a coleta seletiva mostra-se mais promissora uma vez que pode se beneficiar da infraestrutura física e administrativa já existente para captação de materiais recicláveis, possibilitando ainda que sejam criadas outras ações socioambientais entre empresas e cooperativas.

Cabe ainda ressaltar que a nova Política Nacional dos Resíduos Sólidos introduz o conceito de responsabilidade compartilhada sobre a destinação de produtos pós-consumo, o que reforça iniciativas neste sentido.

Além de ser um grande desafio envolvendo diferentes esferas da sociedade civil, a logística reversa também pode ser vista como uma ferramenta estratégica de competitividade empresarial.

\section{AGRADECIMENTOS}

Os autores agradecem à ESCAS pelo auxílio científico na elaboração e desenvolvimento deste estudo, e à Alpargatas S/A pela parceria institucional e suporte financeiro ao estudo realizado.

\section{REFERÊNCIAS}

ABEP - Associação Brasileira de Empresas de Pesquisa. Dados com base no Levantamento Sócio-Econômico 2008 - IBOPE 2010.

AKATU - Instituto Akatu pelo Consumo Consciente. Disponível em: http://www.ressoar.org.br Acesso em 20 novembro 2010.

AQUINO, I.; CASTILHO JR.; A.; PIRES, T. A organização em rede dos catadores de materiais recicláveis na cadeia produtiva reversa de pós-consumo da região da grande Florianópolis: uma alternativa de agregação de valor. Gestão \& Produção, v.16, n.1, p.15-24, 2009. 
ARAUJO, A. C.; MATSUOKA, E. M.; UNG, J. E.; HILSDORF, W. C. Sampaio, M. Logística reversa no comercio eletrônico: um estudo de caso. Gestão \& Produção, vol.20, no.2 São Carlos. 2013

BERTHIER, H. C. Garbage, work and society. Resources, Conservation and Recycling. US: Elsevier Science, v. 39, n.3, 2003, p. 193-210.

BIDONE, F.R.A. Metodologias e técnicas de minimização, reciclagem, e reutilização de resíduos sólidos urbanos. ABES, Rio de Janeiro, 65 p. 1999.

BORCHARDT, M.; POLTOSI, L.; SELLITTO, M.; PEREIRA, G. Considerações sobre ecodesign: um estudo de caso na indústria eletrônica automotiva. Ambiente \& Sociedade, v.11, n.2, p.341-353, 2008.

CEMPRE - Compromisso Empresarial para a Reciclagem. Disponível em: http://www.cempre.org.br. Acesso em : 17 de abril de 2014.

ELKINGTON, J. Canniblas with forks - The triple bottom line of 21st century business. London: Ed. Capstone Publishing Ltd., Oxford.1997.

GRIMBERG, E.; BLAUTH, P. Coleta Seletiva: reciclando materiais, Reciclando valores. Polis: estudos, formação e assessoria em políticas sociais, Revista Polis - Instituto de Estudos, Formação e Assessoria em Políticas Sociais. Ed.31. São Paulo, 1998.

IBGE. Instituto Brasileiro de Geografia e Estatística. Censo Demográfico 2010. Disponível em http://www. ibge.gov.br. Acesso em abril de 2014.

LEITE, P.R. Logística Reversa: meio ambiente e competitividade. São Paulo: Ed. Pearson Prentice Hall, 2009.

HOORNWEG, D.; BHADA-TATA, P. What a Waste - A Global Review of Solid Waste Management. The World Bank, Urban Development Series, No. 15, 2012.

JACOBI, P. Apresentação. In: JACOBI. P. (org.) Gestão compartilhada dos resíduos sólidos no Brasil: inovação com inclusão social. São Paulo: Annablume, 2006, p. 9-16.

MMA - Ministério do Meio Ambiente. Consumo Consciente. Disponível em http://www.brasil.gov.b/consumo-consciente. Acesso em novembro de 2010.

MONTEIRO, C. Como funciona o consumo consciente. Disponível em: http://www.ambiente.hsw.uol.com. br/consumo-consciente.htm/printable. Acesso em novembro de 2010.

PIETERS, R. Changing, garbage disposal patterns of consumers: motivation, ability, and performance. Journal of Public Policy and Marketing, US: AMA, v. 10, 1991.

PREFEITURA DA CIDADE DE JOÃO PESSOA : Emlur coleta 93 mil toneladas de lixo na Capital em três meses (reportagem de 09 de abril de 2012). Disponível em: http://www.joaopessoa.pb.gov.br. Acesso em julho de 2013.

PREFEITURA MUNICIPAL DE SÃO PAULO. Programa de Coleta Seletiva. Disponível em: http://www. prefeitura.sp.gov.br. Acesso em julho de 2013.

NASCIMENTO, I. Grande debate - Nova lei que objetiva disciplinar o descarte de resíduos sólidos traz avanços, mas ainda deixa muitas dúvidas no ar. Revista da Indústria, p.53-55, outubro de 2010.

ROGERS, D. S.; TIBBEN-LEMBKE, R. S. Going backwards: reverse logistics trends and practices. Reno: University of Nevada, 1999. 
SILVÉRIO, S. Secretário do Ministério do Meio Ambiente discursa em Indusnet Fiesp sobre a Política Nacional de Resíduos Sólidos. Disponível em: http://www.fiesp.com.br. Acesso em outubro de 2010.

SKINNER, L. R.; BRYANT, P. T.; RICHEY, R. G. Examining the impact of reverse logistics disposition strategies. International Journal of Physical Distribution \& Logistics Management, v. 38, n. 7, p. 518-539, 2008.

STOCK, J. R.; MULKI, J. P. Product returns processing: an examination of practices of manufacturers, wholesalers/distributors, and retailers. Journal of Business Logistics, n. 30, v. 1, p. 33-52, 2009.

ZANIN, M.; MANCINI, S. D. Resíduos Plásticos e reciclagem: aspectos gerais e tecnologia. São Carlos: Edusfcar, 2004, 143 p.

\section{ANEXOS}

\section{ANEXo I:}

Questionários aos consumidores

1. Você mora nesta cidade? (apenas moradores serão entrevistados)

2. Em que bairro você mora?

3. Lá existe coleta seletiva? (S)im / (N)ão

4. Você separa o lixo para a coleta seletiva? (S)im / (N)ão

5. Você usa sandálias Havaianas? (a) Sim; (b) Não, não uso sandálias de borracha; (c) Não, mas uso de outras marcas. (Obs.: Se "Não", ir para as perguntas 14, 15, 16 e 17).

6. Quantos pares você possui?

7. Onde você costuma comprar sandálias Havaianas? (a) Loja Havaianas; (b) supermercado; (c) loja de calçados; (d) feira; (e) outro

8. Com que freqüência você costuma comprar sandálias Havaianas? par(es) a cada ano(s)

9. O que você costuma fazer com as Sandálias Havaianas usadas? (a) jogo no lixo comum; (b) jogo no lixo reciclável; (c) dôo para alguém; (d) não me lembro; (e) nunca joguei fora. (Obs.: neste caso ignorar a próxima pergunta); (f) outro

10. Com que freqüência você descarta suas sandálias Havaianas? par(es) a cada ano(s)

11. Se a Havaianas começasse um programa de reciclagem das sandálias usadas, em quais destes locais você estaria disposto a ir para descartar o produto usado? (a) Loja Havaianas; (b) supermercado; (c) pontos de coleta seletiva públicos; (d) outro (e) não iria a nenhum lugar. (Obs.: se essa foi a resposta, responder a pergunta 12)

12. Sabendo que solados sandálias de borracha levam até 80 anos para se decompor na natureza, em quais destes locais você estaria disposto a ir para descartar o produto usado? (a) Loja Havaianas; (b) supermercado; (c) pontos de coleta seletiva públicos; (d) outro (e) não iria a nenhum lugar

13. O que a Havaianas poderia fazer que servisse de estímulo adicional para você devolver as sandálias usadas? (a) ganhar desconto na compra de uma sandália nova; (b) acumular pontos que pudessem ser trocados por outros produtos da marca; (c) não preciso de incentivos, devolveria voluntariamente; (d) outro

14. Sexo: (M)asculino / (F)eminino

15. Escolaridade: (1) não alfabetizado; (2) fundamental; (3) médio; (4) superior; (5) pós-graduação

16. Faixa etária: (1) até 20 anos; (2) 20-29; (3) 30-39; (4) 40-49; (5) 50-59; (6) 60 ou mais

17. Renda familiar: (1) até 580 reais; (2) de 581 a 799; (3) 800 a 1499; (4) 1500 a 5000; (5) mais de 5000.

ANEXO II

Questionário às cooperativas

1. Quais materiais vocês recolhem e separam para a reciclagem? (a) papel e papelão; (b) plástico; (c) alumínio; (d) vidro; (e) embalagem tetrapak; (f) sucata; (g) outro

2. Qual a quantidade do recolhimento ( $\mathrm{kg} / \mathrm{semana})$ e quanto recebem por cada um deles $(\mathrm{R} \$ / \mathrm{kg})$ ?

3. Vocês mesmos levam os materiais até a indústria recicladora? Se não, quanto custa o frete?

4. Quantas Havaianas usadas costumam aparecer na triagem (pares/semana)?

5. Vocês têm algum projeto para triar e comercializar borracha usada?

6. Quanto seria um valor justo a receber para coletar, triar e armazenar Havaianas usadas? (R $\$ / \mathrm{kg}$ ) 